\title{
Association of health warning labels and motivation to quit waterpipe tobacco smoking among university students in the Eastern Mediterranean Region
}

Dina Farran', Grace Khawam 1,2, Rima Nakkash', Juhan Lee ${ }^{3}$, Niveen Abu-Rmeileh ${ }^{4}$, Muhammad W. Darawad ${ }^{5}$, Aya Mostafa ${ }^{6}$, Khalid A. Kheirallah7, Mohamed Salama ${ }^{8}$, Randah R. Hamadeh ${ }^{9}$, James F. Thrasher ${ }^{10}$, Ramzi G. Salloum ${ }^{1,11}$

\begin{abstract}
INTRODUCTION This study aimed to determine associations between health warning label content and motivation to quit waterpipe smoking by gender and smoking location.

METHODS Convenience samples of university students in three Eastern Mediterranean countries - Egypt $(n=442)$, Jordan $(n=535)$ and Palestine $(n=487)$ - completed an online survey assessing health warning labels. Multinomial logit regression models were conducted to determine the association between different variables, particularly gender and smoking location, with motivation to quit.

RESULTS In Palestine, female smokers were more motivated to quit waterpipe smoking when seeing textual warning labels related to children (T2) and pregnancy (T6) [T2: 1.8 (95\% CI: 1.1-2.8), T6: 2.7 (95\% CI: 1.6-4.3)] compared to males. Similar results were found in Jordan [T2: 1.6 (95\% CI: 1.0-2.6), T6: 1.8 (95\% CI: 1.1-3.0)]. As for the smoking location, home-only smokers in Palestine were more likely to quit in response to the following warnings: waterpipe smoking is addictive T1: 2.3 (95\% CI: 1.4-3.7), harmful for children T2: 2.3 (95\% CI: 1.4-4.1), harmful for the baby during pregnancy T6: 2.4 (95\% CI: 1.3-4.3), and to believe that quitting reduces the health risks T9: 1.8 (95\% CI: 1.0-3.1). These results were not found in Jordan nor Egypt. Smokers reported that the most noticeable location of a HWL on a waterpipe device is the mouthpiece.

CONCLUSIONS A better understanding of motivation to quit and its association with various warnings and smoking location could guide countries on which warnings to require in legislation and where best to require them particularly in relation to location.
\end{abstract}

\section{AFFILIATION}

1 Department of Health Promotion and Community Health, Faculty of Health Sciences, American University of Beirut, Beirut, Lebanon 2 Centre for Development and Emergency Practices, Oxford Brookes University, Oxford, United Kingdom 3 College of Health and Human Performance, University of Florida, Gainesville, United States 4 Institute of Community and Public Health, Birzeit University, Birzeit, Palestine

5 School of Nursing, The University of Jordan, Amman, Jordan 6 Faculty of Medicine, Ain Shams University, Cairo, Egypt 7 Faculty of Medicine, Jordan University of Science and Technology, Irbid, Jordan 8 Institute of Global Health and Human Ecology, American University in Cairo, Cairo, Egypt

9 College of Medicine and Medical Sciences, Arabian Gulf University, Manama, Bahrain 10 Arnold School of Public Health, University of South Carolina, Columbia, United States 11 College of Medicine, University of Florida, Gainesville, United States

CORRESPONDENCE TO

Rima Nakkash. Department of Health Promotion and Community Health, Faculty of Health Sciences, American University of Beirut, Beirut, Lebanon. E-mail: rn06@aub. edu.lb

KEYWORDS

students, warning labels, motivation to quit, university, waterpipe

Received: 7 December 2020

Revised: 1 March 2021

Accepted: 17 March 2021 


\section{INTRODUCTION}

Waterpipe tobacco smoking (WTS), a traditional tobacco use method that involves the heating of tobacco using charcoal and the inhalation of smoke after passing through water ${ }^{1}$, has been used in the Eastern Mediterranean Region for many centuries with evidence of growing popularity in recent years. A recent systematic review in 68 countries concluded that the prevalence of WTS is highest among adults in the Eastern Mediterranean (EM) Region, and among youth the prevalence was about equal between the EM and European regions ${ }^{2}$. Secondary analysis of the Global Youth Tobacco Survey reported that the highest prevalence rates in the EM region were in Lebanon $(36.9 \%)$ and the West Bank of Palestine (32.7\%) among students aged 13-15 years ${ }^{3}$. In Jordan, a study of university students $(n=1845)$ reported $30 \%$ prevalence for past 30-day WTS ${ }^{4}$. In Egypt, $22.5 \%$ of university students reported to be waterpipe smokers ${ }^{5}$. A systematic review of waterpipe smoking prevalence among university students in Arab countries showed that males had significantly higher rates than females in most of the countries, the highest rates for males being in Egypt, Jordan and Palestine ${ }^{6}$. Several studies showed further gender differences among university students in Arab countries with relation to prevalence ${ }^{4}$, to perception of harm ${ }^{7}$, WTS initiation and smoking behavior $^{8}$, females showing higher levels of perceived harm and lower levels of heavy smoking behaviors.

This increase in its popularity has been attributed to the introduction of sweet and aromatic tobacco flavors, increased social acceptability, especially among youth and women, the misperception that waterpipe is safer than cigarettes, and weaklyenforced waterpipe smoking control regulations ${ }^{9}$. Among youth, the spread of WTS is partly driven by the lack of awareness of the health risks associated with smoking ${ }^{1,10}$. One of the most effective population-based strategies to communicate the harms of smoking is the use of health warning labels (HWLs) ${ }^{11,12}$. A recent US study showed significant differences among participants based on their exposure to HWLs, with those not exposed having more puffs, reporting more satisfaction and reporting lower harm perception in WTS compared to those exposed to the HWLs ${ }^{13}$. HWLs have been evidenced to increase motivation to quit among university student smokers in the US ${ }^{14,15}$ and in Arab countries ${ }^{9,16,17}$. While these studies have showed various attitudinal responses to text and pictorial HWLs among university students who smoke waterpipe, no study has yet examined the differential responses to various HWLs including motivation to quit between male and female smokers in Arab countries. Analyzing gender differences by varying thematic warnings can help to better target appropriate gender specific interventions.

Although Article 11 of the World Health Organization (WHO) Framework Convention on Tobacco Control (FCTC) has clearly recommended parties to adopt HWLs on all tobacco products, current WTS labels do not abide by the policies in terms of pictorial health warning, packaging, font warning size, and labelling of tobacco constituents ${ }^{18}$. Also, waterpipe HWLs are mostly present on tobacco packs, meaning that many users are rarely exposed to them ${ }^{19,20}$. In a qualitative study, adult smokers and non-smokers in Egypt stated that the placement of pictorial HWLs on the waterpipe device (as opposed to tobacco packs) would increase warning visibility, reduce intent for WTS initiation, and increase willingness to quit ${ }^{21}$. It was also suggested that pictorial HWLs should be placed on the waterpipe's body, mouthpiece or hose ${ }^{21}$, however no study has yet determined the differential preference (if any) of the placement of the HWL on the waterpipe device by gender. Determining the optimal locations to place warning labels by target group could be valuable for future interventions and policy recommendations.

Café smokers are a particular group of smokers rarely exposed to HWL. In fact, figures have shown that $43 \%$ to $74 \%$ of young waterpipe users who smoke in cafés are not exposed to the HWLs ${ }^{22}$. This is of public health significance, given the increasing WTS café culture in the Eastern Mediterranean region, which is contributing to the social acceptability of waterpipe smoking. In Egypt, 64\% of university students who are waterpipe smokers preferred smoking in a traditional café, $27 \%$ in a modern one (like restaurants), and only $2 \%$ preferred smoking waterpipe at home ${ }^{5}$. The slow pace and long sessions of WTS are conducive to social interactions among family and friends particularly within social gatherings in café settings ${ }^{23}$. Nakkash et al. ${ }^{22}$ reported in their 
qualitative study assessment that the availability of waterpipe in cafés and restaurants has contributed to a rise in $\mathrm{WTS}^{24}$, no study has yet examined the relationship between waterpipe smoking location (at the café vs at home), exposure to HWLs and motivation to quit.

Knowing that WTS is associated with multiple health risks, this study aims to explore the association between HWLs and the motivation to quit WTS among university students in three Eastern Mediterranean countries (Egypt, Jordan and Palestine), and to assess whether motivation to quit varies by type and message of the HWL, gender and by location of WTS (i.e. at home and café). We also investigate differences for the preferred location of the HWL on the waterpipe device among males and females in each of the three countries.

\section{METHODS}

\section{Participants}

This cross-sectional study was conducted in 2016 in three Eastern Mediterranean countries: Egypt, Jordan and Palestine. Data were collected from university students who were ever waterpipe smokers. Convenience sampling was used to recruit participants from university campuses using flyers and announcements via emails. Inclusion criteria were: 1) being between the ages of 18 and 29 years, 2) being a current university student, and 3) having smoked at least one or two puffs of waterpipe tobacco at least once, i.e. ever WTS. After obtaining consent, participants were provided access to the online survey, which was available in both English and Arabic. The study protocol was approved by the institutional review boards of all participating universities. No financial incentives were provided to participants. Additional details of the sampling and recruitment methods are available elsewhere.

\section{Demographic characteristics and cigarette smoking}

The questionnaire was adopted from previous research on waterpipe use among university students and assessed: demographics, attitudes towards waterpipe smoking, waterpipe smoking history and preferences, and reactions to $\mathrm{HWLs}^{25}$. Demographic characteristics included age (in years), gender (male or female), educational level (bachelor's degree or less, enrolled in postgraduate degree program, or enrolled in a medical degree program), and employment status (employed or not employed). In addition to demographics, the survey assessed whether the participant smoked cigarettes in the past 30 days. Those who reported smoking on at least 1 day were categorized as current cigarettes smokers.

\section{Waterpipe health warning labels}

The HWL section consisted of nine text-only messages and four messages that included both text and pictorial imagery. Labels assessed were previously developed by Nakkash et al. ${ }^{18}$. Text-only HWLs included the following messages, each placed after the word 'WARNING': Waterpipe smoking is addictive (T1); Waterpipe smoke can harm children (T2); Waterpipe smoking causes fatal lung disease (T3); Waterpipe smoking causes cancer (T4); Waterpipe smoking causes strokes and heart disease (T5); Waterpipe smoking during pregnancy can harm the baby (T6); Waterpipe smoking can kill you (T7); Waterpipe smoke causes fatal lung disease in nonsmokers (T8); and Quitting waterpipe smoking now greatly reduces serious risks to your health (T9). Pictorial HWLs consisted of pictures coupled with one of the following messages: The water in waterpipe does not prevent toxic materials from reaching your body (P1); Waterpipe smoke contains a substance also found in rat poison (P2); Protect your children: Don't let them be exposed to waterpipe smoke (P3); and Despite its pleasant smell, waterpipe smoke kills (P4) (Supplementary file, Figure 1). Current waterpipe users were asked if the text only and pictorial HWLs would motivate them to quit waterpipe smoking.

The actual response choices were: not at all, a little, a lot, and completely. These response items were collapsed into yes and no. Participants were also shown an image of options for HWL placement on the waterpipe device (i.e. device base, stem, hose, and mouthpiece; see Supplementary file, Figure 2) and asked where they think the HWL would be most noticeable.

\section{Waterpipe tobacco smoking measures}

Current waterpipe smoker was defined as any respondent who smoked waterpipe at least once in the past 30 days at the time of the survey. Participants were asked about the place where they usually smoke 
waterpipe tobacco (own home, someone else's home, university accommodation, café/restaurant or other locations). We defined 'At home only' waterpipe tobacco smokers as any current waterpipe smoker who reported that they smoked waterpipe 'in their own home', 'in someone else's home' or 'university accommodations' and responded as almost always/ always, usually/most of the time or often. We defined 'in cafés only' waterpipe tobacco smoker as those current waterpipe smokers who reported that they smoked waterpipe 'in a café/restaurant' almost always/ always, usually/most of the time or often. Those who responded to both were defined as smokers both at home and cafes whereas those who smoked in all other places were considered as smokers in 'other locations'.

\section{Statistical analysis}

The analytic sample is a sub set of a broader sample of ever smokers. The analysis was conducted in each country to assess: 1) participants' motivation to quit in response to textual health warning labels; 2 ) participants' motivation to quit in response to pictorial health warning labels; and 3 ) the most noticeable location of a HWL on a waterpipe device by gender. In the descriptive analysis, means and standard deviations were calculated for continuous variables, and percent prevalence was reported for categorical variables. Chi-squared tests were done to determine the most noticeable location of a health warning label on a waterpipe device by gender. Additionally, multinomial logit regression models were used to determine the association of different variables with motivation to quit smoking in response to the health warning labels. Significant differences were reported at a $\mathrm{p}<0.05$. All statistical analyses were performed using SPSS version 25.

\section{RESULTS}

The number of students who completed the survey was 728 in Egypt (72.5\% males), 790 (62.9\% males) in Jordan and 772 in Palestine (47.9\% males). The mean age was 20.6 years (SD: 2.2), 21 years (SD: 2.2 ) and 23.8 years (SD: 2.8) in Palestine, Jordan and Egypt, respectively. Out of the total number of university students surveyed, the proportion of current waterpipe smokers was 73.8\% in Egypt, 68.4\% in Jordan and $63.2 \%$ in Palestine (Table 1).

\section{Placement of health warning label}

In all three countries, current waterpipe smokers reported that the most noticeable location of a HWL on a waterpipe device is the mouthpiece (Table 2 ). The proportion of female university students who chose the mouthpiece was higher compared to males in all countries. Among female current waterpipe smokers, $60.3 \%$ in Palestine, $58.0 \%$ in Jordan and $54.1 \%$ in Egypt selected the mouthpiece as the most noticeable location for a HWL; whereas among male current users, $54.1 \%$ in Palestine, $52.9 \%$ in Jordan and $45.6 \%$ in Egypt selected it. The mouthpiece was followed in ranking by the stem, the base and the hose across countries and genders, except for Palestine, where male current users preferred the base (24.4\%) over the stem (19.4\%). In all countries and for both genders, the hose was considered the location where the HWL can be least noticed (Table 2).

\section{Motivation to quit (pictorial warnings)}

In all countries, the HWL P3 'Protect your children: Don't let them be exposed to waterpipe smoke' was more likely to motivate current waterpipe smokers to quit while the label P1 'The water in waterpipe does not prevent toxic materials from reaching your body' was the least effective (data not shown). When studying the association of gender with motivation

Table 1. Characteristics of current waterpipe smokers by country

\begin{tabular}{lccc} 
& $\begin{array}{c}\text { Palestine } \\
(n=487)\end{array}$ & $\begin{array}{c}\text { Jordan } \\
(n=535)\end{array}$ & $\begin{array}{c}\text { Egypt } \\
(n=442)\end{array}$ \\
& $n(\%)$ & $n(\%)$ & $n(\%)$ \\
\hline $\begin{array}{l}\text { Age (years), mean } \pm \text { SD } \\
\text { Gender }\end{array}$ & $20.6 \pm 2.2$ & $21.0 \pm 2.2$ & $23.8 \pm 2.8$ \\
Female & $232(47.6)$ & $189(35.3)$ & $40(9.1)$ \\
Male & $250(51.3)$ & $345(64.5)$ & $395(89.4)$ \\
Education level & & & \\
Bachelor's degree or less & $427(87.7)$ & $432(80.8)$ & $312(70.6)$ \\
Medical degree & $3(0.6)$ & $82(15.3)$ & $26(5.9)$ \\
Postgraduate & $38(7.8)$ & $15(2.8)$ & $72(16.3)$ \\
Employment status & & & \\
Not employed & $286(58.7)$ & $356(66.5)$ & $147(33.3)$ \\
Employed & $137(28.1)$ & $139(26.0)$ & $252(57.0)$ \\
Past 30-day cigarette & & & \\
smoking & & & \\
No & $307(63.0)$ & $318(59.4)$ & $183(41.4)$ \\
Yes & $161(33.1)$ & $209(39.1)$ & $230(52.0)$
\end{tabular}


to quit in response to pictorial health warning labels, no significant differences were seen among males and females in all countries (Table 3 ). As for the smoking location, the label that mostly motivated participants to quit smoking in all smoking locations was the one asking smokers to protect their children, with respondents in Egypt showing the highest endorsement (71.9\%) (data not shown). When studying the association of smoking location with motivation to quit, home-only smokers in Palestine were 2 times more motivated to quit than home and café smokers when seeing the pictorial warning label 'The water in waterpipe does not prevent toxic materials from reaching your body' P1: 2 (95\% CI: 1.1-3.3) and when seeing the warning 'Protect your children: Don't let them be exposed to waterpipe smoke' P3: 1.9 (95\% CI: 1.2-3.2), controlling for age, gender, education level, employment status, and past 30-day cigarette use. These results were not detected in Jordan nor in Egypt. Smokers who smoke in other locations seem to have the highest motivation to quit as response to all 4 pictorial HWL in both Palestine and Jordan, whereas this was not observed in Egypt.

Table 2. Reported most noticeable health warning label location among current waterpipe smokers by gender

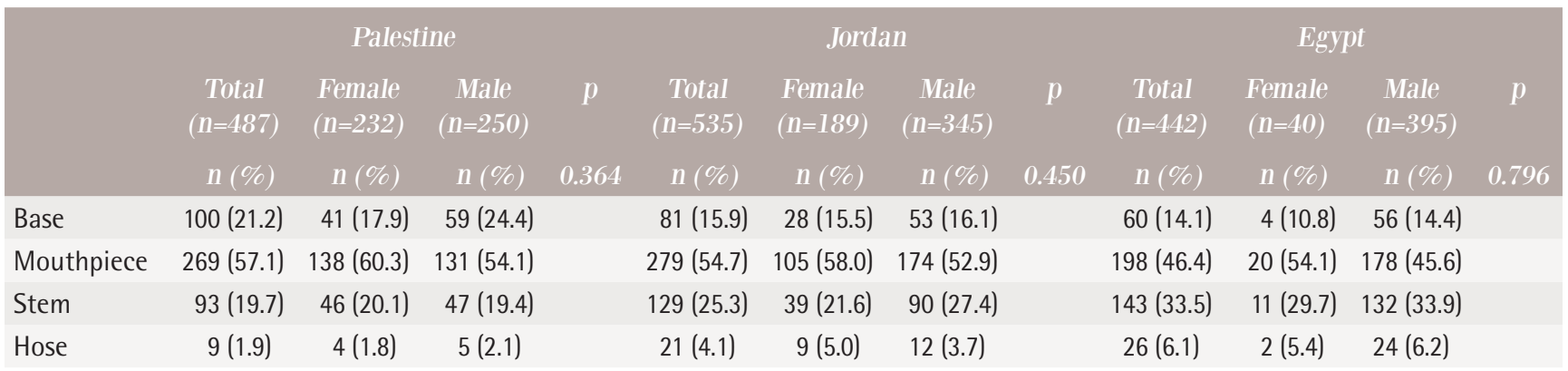

Table 3. Association of different variables with motivation to quit in response to pictorial health warning labels using multinomial logit regression model

\begin{tabular}{|c|c|c|c|c|c|c|c|c|c|c|c|c|}
\hline \multirow[t]{2}{*}{ Variable } & \multicolumn{4}{|c|}{ Palestine } & \multicolumn{4}{|c|}{ Jordan } & \multicolumn{4}{|c|}{ Egypt } \\
\hline & $P I$ & P2 & P3 & P4 & $P 1$ & P2 & P3 & P4 & $P 1$ & P2 & P3 & P4 \\
\hline Age ( $\geq 21$ years) & $\begin{array}{c}1.3 \\
(0.8-2.0)\end{array}$ & $\begin{array}{c}1.0 \\
(0.7-1.6)\end{array}$ & $\begin{array}{c}1.0 \\
(0.7-1.5)\end{array}$ & $\begin{array}{c}0.8 \\
(0.5-1.2)\end{array}$ & $\begin{array}{c}1.0 \\
(0.7-1.4)\end{array}$ & $\begin{array}{c}0.8 \\
(0.6-1.2)\end{array}$ & $\begin{array}{c}1.1 \\
(0.7-1.6)\end{array}$ & $\begin{array}{c}1.0 \\
(0.7-1.4)\end{array}$ & $\begin{array}{c}1.0 \\
(0.6-1.7)\end{array}$ & $\begin{array}{c}0.7 \\
(0.4-1.2)\end{array}$ & $\begin{array}{c}1.0 \\
(0.5-1.8)\end{array}$ & $\begin{array}{c}0.8 \\
(0.5-1.3)\end{array}$ \\
\hline Gender (female) & $\begin{array}{c}0.9 \\
(0.6-1.4)\end{array}$ & $\begin{array}{c}1.4 \\
(0.9-2.1)\end{array}$ & $\begin{array}{c}1.3 \\
(0.9-2.0)\end{array}$ & $\begin{array}{c}0.9 \\
(0.6-1.4)\end{array}$ & $\begin{array}{c}1.1 \\
(0.8-1.6)\end{array}$ & $\begin{array}{c}1.2 \\
(0.8-1.8)\end{array}$ & $\begin{array}{c}1.3 \\
(0.9-1.9)\end{array}$ & $\begin{array}{c}1.3 \\
(0.9-1.9)\end{array}$ & $\begin{array}{c}0.8 \\
(0.4-1.6)\end{array}$ & $\begin{array}{c}1.0 \\
(0.5-2.0)\end{array}$ & $\begin{array}{c}1.0 \\
(0.4-2.2)\end{array}$ & $\begin{array}{c}1.2 \\
(0.6-2.6)\end{array}$ \\
\hline $\begin{array}{l}\text { Education } \\
\text { (postgraduate) }\end{array}$ & $\begin{array}{c}1.1 \\
(0.5-2.4)\end{array}$ & $\begin{array}{c}1.0 \\
(0.5-2.1)\end{array}$ & $\begin{array}{c}1.2 \\
(0.6-2.6)\end{array}$ & $\begin{array}{c}1.7 \\
(0.8-3.6)\end{array}$ & $\begin{array}{c}1.3 \\
(0.8-2.1)\end{array}$ & $\begin{array}{c}1.7^{*} \\
(1.1-2.7)\end{array}$ & $\begin{array}{c}1.6^{*} \\
(1.0-2.6)\end{array}$ & $\begin{array}{c}1.1 \\
(0.7-1.8)\end{array}$ & $\begin{array}{c}1.4 \\
(0.8-2.6)\end{array}$ & $\begin{array}{c}1.2 \\
(0.7-2.1)\end{array}$ & $\begin{array}{c}1.3 \\
(0.7-2.6)\end{array}$ & $\begin{array}{c}1.6 \\
(0.9-3.0)\end{array}$ \\
\hline $\begin{array}{l}\text { Working status } \\
\text { (not employed) }\end{array}$ & $\begin{array}{c}1.3 \\
(0.8-2.2)\end{array}$ & $\begin{array}{c}1.2 \\
(0.7-1.8)\end{array}$ & $\begin{array}{c}1.3 \\
(0.8-2.0)\end{array}$ & $\begin{array}{c}1.0 \\
(0.6-1.6)\end{array}$ & $\begin{array}{c}0.7 \\
(0.5-1.1)\end{array}$ & $\begin{array}{c}0.9 \\
(0.6-1.3)\end{array}$ & $\begin{array}{c}1.0 \\
(0.6-1.4)\end{array}$ & $\begin{array}{c}0.8 \\
(0.6-1.2)\end{array}$ & $\begin{array}{c}0.5^{*} \\
(0.3-0.8)\end{array}$ & $\begin{array}{c}0.4^{*} \\
(0.3-0.7)\end{array}$ & $\begin{array}{c}0.3^{*} \\
(0.2-0.6)\end{array}$ & $\begin{array}{c}0.4^{*} \\
(0.2-0.7)\end{array}$ \\
\hline $\begin{array}{l}\text { Smoked } \\
\text { cigarettes in } \\
\text { past } 30 \text { days }\end{array}$ & $\begin{array}{c}0.9 \\
(0.5-1.4)\end{array}$ & $\begin{array}{c}0.9 \\
(0.6-1.4)\end{array}$ & $\begin{array}{c}0.7 \\
(0.5-1.1)\end{array}$ & $\begin{array}{c}0.6^{*} \\
(0.4-1.0)\end{array}$ & $\begin{array}{c}0.8 \\
(0.5-1.1)\end{array}$ & $\begin{array}{c}0.9 \\
(0.6-1.3)\end{array}$ & $\begin{array}{c}0.9 \\
(0.6-1.3)\end{array}$ & $\begin{array}{c}1.0 \\
(0.7-1.4)\end{array}$ & $\begin{array}{c}0.3^{*} \\
(0.2-0.5)\end{array}$ & $\begin{array}{c}0.3^{*} \\
(0.2-0.5)\end{array}$ & $\begin{array}{c}0.5^{*} \\
(0.3-0.9)\end{array}$ & $\begin{array}{c}0.2^{*} \\
(0.1-0.4)\end{array}$ \\
\hline \multicolumn{13}{|c|}{ Smoking location (café and home) } \\
\hline Café only & $\begin{array}{c}1.2 \\
(0.7-2.1)\end{array}$ & $\begin{array}{c}1.5 \\
(0.9-2.5)\end{array}$ & $\begin{array}{c}1.7 \\
(1-2.7)\end{array}$ & $\begin{array}{c}1.4 \\
(0.8-2.4)\end{array}$ & $\begin{array}{c}1.1 \\
(0.7-1.6)\end{array}$ & $\begin{array}{c}1.5 \\
(1.0-2.3)\end{array}$ & $\begin{array}{c}1.1 \\
(0.8-1.8)\end{array}$ & $\begin{array}{c}1.4 \\
(0.9-2.3)\end{array}$ & $\begin{array}{c}0.8 \\
(0.5-1.4)\end{array}$ & $\begin{array}{c}0.8 \\
(0.5-1.4)\end{array}$ & $\begin{array}{c}1.0 \\
(0.5-1.8)\end{array}$ & $\begin{array}{c}0.9 \\
(0.5-1.5)\end{array}$ \\
\hline Home only & $\begin{array}{c}2^{*} \\
(1.1-3.3)\end{array}$ & $\begin{array}{c}1.3 \\
(0.8-2.2)\end{array}$ & $\begin{array}{c}1.9^{*} \\
(1.2-3.2)\end{array}$ & $\begin{array}{c}1.5 \\
(0.9-2.5)\end{array}$ & $\begin{array}{c}0.7 \\
(0.5-1.1)\end{array}$ & $\begin{array}{c}1.4 \\
(0.9-2.2)\end{array}$ & $\begin{array}{c}1.4 \\
(0.9-2.2)\end{array}$ & $\begin{array}{c}1.3 \\
(0.9-2.1)\end{array}$ & - & $\begin{array}{c}1.2 \\
(0.2-7.0)\end{array}$ & $\begin{array}{c}0.8 \\
(0.1-4.5)\end{array}$ & $\begin{array}{c}0.7 \\
(0.2-3.5)\end{array}$ \\
\hline Other locations & $\begin{array}{c}3.5^{*} \\
(2.0-6.2)\end{array}$ & $\begin{array}{c}3.3^{*} \\
(1.9-5.7)\end{array}$ & $\begin{array}{c}3.1^{*} \\
(1.7-5.6)\end{array}$ & $\begin{array}{c}3.4^{*} \\
(1.9-6.0)\end{array}$ & $\begin{array}{c}2.6^{*} \\
(1.5-4.5)\end{array}$ & $\begin{array}{c}3.3^{*} \\
(1.9-5.8)\end{array}$ & $\begin{array}{c}3.8^{*} \\
(2.0-7.3)\end{array}$ & $\begin{array}{c}4.3^{*} \\
(2.5-7.7)\end{array}$ & $\begin{array}{c}1.0 \\
(0.1-11.9)\end{array}$ & - & - & - \\
\hline
\end{tabular}

${ }^{*} p<0.05$. P1: The water in waterpipe does not prevent toxic materials from reaching your body. P2: Waterpipe smoke contains a substance also found in rat poison. P3: Protect your children, don't let them be exposed to waterpipe smoke. P4: Despite its pleasant smell, waterpipe smoke kills. Participants making a negative response to the warning label were the reference category. In the smoking location, both café and home smokers were considered as a reference category. 
Table 4. Association of different variables with motivation to quit in response to textual health warning labels using multinomial logit regression model

\begin{tabular}{|c|c|c|c|c|c|c|c|c|c|c|c|c|}
\hline \multirow[t]{2}{*}{ Variable } & \multicolumn{4}{|c|}{ Palestine } & \multicolumn{4}{|c|}{ Jordan } & \multicolumn{4}{|c|}{ Egypt } \\
\hline & $T I$ & $\mathrm{~T} 2$ & T6 & T9 & $T I$ & $\mathrm{~T} 2$ & T6 & T9 & $T 1$ & $\mathrm{~T} 2$ & T6 & T9 \\
\hline Age ( $\geq 21$ years) & $\begin{array}{c}0.8 \\
(0.5-1.2)\end{array}$ & $\begin{array}{c}0.9 \\
(0.5-1.4)\end{array}$ & $\begin{array}{c}0.8 \\
(0.5-1.3)\end{array}$ & $\begin{array}{c}0.6^{*} \\
(0.4-1.0)\end{array}$ & $\begin{array}{c}1.1 \\
(0.8-1.6)\end{array}$ & $\begin{array}{c}1.1 \\
(0.7-1.7)\end{array}$ & $\begin{array}{c}1.0 \\
(0.6-1.6)\end{array}$ & $\begin{array}{c}1.3 \\
(0.8-2.1)\end{array}$ & $\begin{array}{c}0.9 \\
(0.5-1.5)\end{array}$ & $\begin{array}{c}0.9 \\
(0.4-1.8)\end{array}$ & $\begin{array}{c}0.7 \\
(0.3-1.6)\end{array}$ & $\begin{array}{c}0.9 \\
(0.5-1.8)\end{array}$ \\
\hline Gender (female) & $\begin{array}{c}1.1 \\
(0.7-1.6)\end{array}$ & $\begin{array}{c}1.8^{*} \\
(1.1-2.8)\end{array}$ & $\begin{array}{c}2.7^{*} \\
(1.6-4.3)\end{array}$ & $\begin{array}{c}1.4 \\
(0.9-2.1)\end{array}$ & $\begin{array}{c}1.3 \\
(1.0-1.9)\end{array}$ & $\begin{array}{c}1.6^{*} \\
(1.0-2.6)\end{array}$ & $\begin{array}{c}1.8^{*} \\
(1.1-3.0)\end{array}$ & $\begin{array}{c}1.1 \\
(0.7-1.9)\end{array}$ & $\begin{array}{c}1.2 \\
(0.5-2.5)\end{array}$ & $\begin{array}{c}0.5 \\
(0.2-1.2)\end{array}$ & $\begin{array}{c}0.3^{*} \\
(0.1-0.7)\end{array}$ & $\begin{array}{c}1.1 \\
(0.4-2.9)\end{array}$ \\
\hline $\begin{array}{l}\text { Education } \\
\text { (postgraduate) }\end{array}$ & $\begin{array}{c}0.9 \\
(0.4-1.8)\end{array}$ & $\begin{array}{c}1.1 \\
(0.5-2.6)\end{array}$ & $\begin{array}{c}0.8 \\
(0.3-1.8)\end{array}$ & $\begin{array}{c}0.8 \\
(0.4-1.7)\end{array}$ & $\begin{array}{c}1.0 \\
(0.6-1.6)\end{array}$ & $\begin{array}{c}0.8 \\
(0.5-1.4)\end{array}$ & $\begin{array}{c}0.7 \\
(0.4-1.2)\end{array}$ & $\begin{array}{c}0.6 \\
(0.4-1.1)\end{array}$ & $\begin{array}{c}1.3 \\
(0.7-2.3)\end{array}$ & $\begin{array}{c}1.0 \\
(0.4-2.3)\end{array}$ & $\begin{array}{c}1.3 \\
(0.5-3.0)\end{array}$ & $\begin{array}{c}1.3 \\
(0.6-2.8)\end{array}$ \\
\hline $\begin{array}{l}\text { Working status } \\
\text { (not employed) }\end{array}$ & $\begin{array}{c}1.0 \\
(0.6-1.5)\end{array}$ & $\begin{array}{c}1.6 \\
(1.0-2.6)\end{array}$ & $\begin{array}{c}1.5 \\
(0.9-2.6)\end{array}$ & $\begin{array}{c}1.4 \\
(0.9-2.3)\end{array}$ & $\begin{array}{c}0.8 \\
(0.5-1.2)\end{array}$ & $\begin{array}{c}0.7 \\
(0.4-1.2)\end{array}$ & $\begin{array}{c}0.8 \\
(0.5-1.4)\end{array}$ & $\begin{array}{c}1.4 \\
(0.9-2.3)\end{array}$ & $\begin{array}{c}0.3^{*} \\
(0.2-0.5)\end{array}$ & $\begin{array}{c}0.4^{*} \\
0.2-0.8)\end{array}$ & $\begin{array}{c}0.4^{*} \\
(0.2-0.9)\end{array}$ & $\begin{array}{c}0.5 \\
(0.3-1.0)\end{array}$ \\
\hline $\begin{array}{l}\text { Smoked } \\
\text { cigarettes in } \\
\text { past } 30 \text { days }\end{array}$ & $\begin{array}{c}0.5^{*} \\
(0.4-0.8)\end{array}$ & $\begin{array}{c}1.0 \\
(0.6-1.5)\end{array}$ & $\begin{array}{c}0.9 \\
(0.5-1.4)\end{array}$ & $\begin{array}{c}0.6^{*} \\
(0.4-1.0)\end{array}$ & $\begin{array}{c}0.9 \\
(0.6-1.2)\end{array}$ & $\begin{array}{c}1.2 \\
(0.7-1.8)\end{array}$ & $\begin{array}{c}0.9 \\
(0.6-1.4)\end{array}$ & $\begin{array}{c}1.0 \\
(0.6-1.6)\end{array}$ & $\begin{array}{c}0.2^{*} \\
(0.1-0.4)\end{array}$ & $\begin{array}{c}0.5 \\
(0.3-1.0)\end{array}$ & $\begin{array}{c}0.4^{*} \\
(0.2-0.9)\end{array}$ & $\begin{array}{c}0.1^{*} \\
(0.0-0.3)\end{array}$ \\
\hline \multicolumn{13}{|c|}{ Smoking location (café and home) } \\
\hline Café only & $\begin{array}{c}1.5 \\
(0.9-2.5)\end{array}$ & $\begin{array}{c}2.5^{*} \\
(1.4-4.4)\end{array}$ & $\begin{array}{c}2.9^{*} \\
(1.6-5.4)\end{array}$ & $\begin{array}{c}1.9^{*} \\
(1.1-3.3)\end{array}$ & $\begin{array}{c}1.4 \\
(0.9-2.2)\end{array}$ & $\begin{array}{c}1.6 \\
(0.9-2.8)\end{array}$ & $\begin{array}{c}1.7 \\
(1.0-3.1)\end{array}$ & $\begin{array}{c}1.9^{*} \\
(1.1-3.3)\end{array}$ & $\begin{array}{c}0.4^{*} \\
(0.2-0.7)\end{array}$ & $\begin{array}{c}1.0 \\
(0.4-2.1)\end{array}$ & $\begin{array}{c}0.6 \\
(0.2-1.4)\end{array}$ & $\begin{array}{c}0.3^{*} \\
(0.2-0.7)\end{array}$ \\
\hline Home only & $\begin{array}{c}2.3^{*} \\
(1.4-3.7)\end{array}$ & $\begin{array}{c}2.3^{*} \\
(1.4-4.1)\end{array}$ & $\begin{array}{c}2.4^{*} \\
(1.3-4.3)\end{array}$ & $\begin{array}{c}1.8^{*} \\
(1.0-3.1)\end{array}$ & $\begin{array}{c}1.1 \\
(0.7-1.7)\end{array}$ & $\begin{array}{c}1.1 \\
(0.6-1.8)\end{array}$ & $\begin{array}{c}0.9 \\
(0.5-1.5)\end{array}$ & $\begin{array}{c}1.2 \\
(0.7-2.1)\end{array}$ & - & - & $\begin{array}{c}0.6 \\
(0.0-7.3)\end{array}$ & - \\
\hline Other locations & $\begin{array}{c}3.9^{*} \\
(2.2-7.1)\end{array}$ & $\begin{array}{c}3.4^{*} \\
(1.7-6.7)\end{array}$ & $\begin{array}{c}3.1^{*} \\
(1.6-6.4)\end{array}$ & $\begin{array}{c}2.1^{*} \\
(1.1-4.1)\end{array}$ & $\begin{array}{c}3.0^{*} \\
(1.7-5.4)\end{array}$ & $\begin{array}{c}2.0 \\
(0.9-4.2)\end{array}$ & $\begin{array}{c}1.8 \\
(0.8-4.0)\end{array}$ & $\begin{array}{c}3.7^{*} \\
(1.5-9.2)\end{array}$ & $\begin{array}{c}0.6 \\
(0.0-8.7)\end{array}$ & - & - & - \\
\hline
\end{tabular}

${ }^{*} \mathrm{p}<0.05$. T1: Waterpipe smoking is addictive. T2: Waterpipe smoke can harm children. T3: Waterpipe smoking causes fatal lung disease. T4: Waterpipe smoking causes cancer. T5: Waterpipe smoking causes strokes and heart disease. T6: Waterpipe smoking during pregnancy can harm the baby. T7: Waterpipe smoking can kill you. T8: Waterpipe smoke causes fatal lung disease in non-smokers. T9: Quitting waterpipe smoking now greatly reduces serious risks to your health. Only T1, T2, T6 and T9 are presented here because the other warning labels did not show significance. Participants making a negative response to the warning label were the reference category. In the smoking location, both café and home smokers were considered as a reference category.

\section{Motivation to quit (text warnings)}

Table 4 shows participants' motivation to quit in response to text-only HWLs. Not all textual warning labels are reported in this table as some of them did not show significance. In Palestine, female smokers were 1.8 times (95\% CI: 1.1-2.8) more motivated to quit waterpipe smoking when seeing the textual warning label T2: 'waterpipe smoke can harm children' and 2.7 times (95\% CI: 1.6-4.3) more motivated to quit when seeing the warning label T6: 'waterpipe smoking during pregnancy can harm the baby' compared to males. Similar results were found in Jordan [T2: 1.6 (95\% CI: 1.0-2.6); T6: 1.8 (95\% CI: 1.1-3.0)]. In Egypt, the warning label related to pregnancy showed less motivation to quit in females than males T6: 0.3 (95\% CI: 0.1-0.7). As for the smoking location, smokers who smoke at home only in Palestine were 2 times more likely to consider waterpipe smoking as addictive T1: 2.3 (95\% CI: 1.4-3.7), harmful for children T2: 2.3 (95\% CI: 1.4-4.1), harmful for the baby during pregnancy T6:
2.4 (95\% CI: 1.3-4.3), and to believe that quitting reduces the health risks T9: 1.8 (95\% CI: 1.0-3.1). Similarly, café only smokers were also more motivated to quit (1.9 to 2.9 times) as a response to $\mathrm{T} 2, \mathrm{~T} 6$, and T9. In contrast, café only smokers in Egypt were 2.5 to 3.3 times less likely to respond to the HWL T1 and T9 [T1: 0.4 (95\% CI: 0.2-0.7 and T9: 0.3 (95\% CI 0.2-0.7)]. Smokers who smoke in other locations (such as at a friend's house, etc.) seem to have the highest motivation to quit as response to all 4 textual HWL in both Palestine and Jordan, whereas this was not observed in Egypt.

\section{DISCUSSION}

The prevalence of waterpipe smoking among youth in the Eastern Mediterranean Region has risen as waterpipe is perceived as less harmful compared to other tobacco products ${ }^{1}$. Since HWLs have been proven effective in conveying the health risks of smoking to the public ${ }^{13,14}$, we report on the effect of these labels on motivation to quit waterpipe 
smoking among university students in the Eastern Mediterranean Region by gender and smoking location. Health warnings communicating the harm of waterpipe smoke to children and fetuses during pregnancy were the most effective at motivating current smokers to quit. This finding is consistent with other research conducted in the region ${ }^{16,26,27}$ as well as in the United States ${ }^{14}$. This might suggest that individuals who are of reproductive age are more concerned about the possible risks of waterpipe smoking to children, infants and childbearing women ${ }^{28}$, and these attitudes can be observed among young people across different countries and cultures. Similar effects of warnings related to child health have been observed among cigarette smokers ${ }^{29}$. These findings are in accordance with a recent international expert panel consensus, where labels related to waterpipe's harmful effects on newborn children were identified as being among the most effective at communicating WTS-related risks ${ }^{30}$. Furthermore, our results show that the motivation to quit in response to text warning labels was significantly higher among females than males for text warnings related to harm to children or during pregnancy. Similar genderspecific findings can be found in studies evaluating the effect of HWLs related to pregnancy and child health on $\mathrm{WTS}^{31}$ as well as on cigarette smoking ${ }^{29,32}$. These findings confirm the need for gender-specific considerations in the design of interventions and policies to reduce tobacco smoking and/or increase the motivation to quit.

The theory of planned behavior ${ }^{33}$ and the extended parallel process model ${ }^{15}$ have been suggested to inform the investigation of factors affecting WTS behavior and intention to quit, although these theories had not been previously applied to assess the effect of waterpipe HWLs on intention to quit. In extrapolation, such theorybased studies have been conducted to address HWLs in cigarette smoking. Using the extended parallel process model, motivation to quit cigarette smoking was targeted by emphasizing the need for messaging that 'should contain both threat and efficacy messages to increase risk perceptions and efficacy beliefs ${ }^{28}$. Health warnings communicating the negative consequences of WTS to others such as harm to fetuses, infants and children were found to increase respondents' motivation to quit. These findings may reflect a general moral need to protect the health of children who may be perceived as vulnerable, suggesting that perceived severity and negative emotional reactions such as concern for others may be primary factors contributing to intention to quit ${ }^{28}$. More theory-driven research should be conducted to understand the factors affecting attitudinal and behavioral responses to waterpipe HWLs.

The social dimension of WTS as well as the emergence of café culture in Eastern Mediterranean countries have contributed to the increased popularity of WTS among youth ${ }^{1}$. Although previous studies have shown how HWLs focusing on harm to self and to others motivated youth to quit WTS ${ }^{9,16}$, no study has yet assessed motivation to quit by pattern of usual or preferred smoking location. In our study, we found that home-only smokers and café-only smokers can be motivated to quit in response to text warning labels related to health (i.e. harm to self) and labels related to pregnancy and children (i.e. harm to others), whereas pictorial warnings do not seem to differentially affect café-only smokers. We also observed a negative or opposite reaction in Egypt, where café-only smokers consistently showed lowest motivation to quit in response to both pictorial and text HWLs. This may be partly due to the difference in cultural background, the social acceptability and the social norms associated with smoking which affect to a large extent the motivation to quit waterpipe smoking. In Egypt, the majority of university students prefer to smoke at a café or local restaurant ${ }^{5}$. Café customers were considered as established smokers in a study conducted in Syria, and established smokers showed less willingness to quit ${ }^{34}$. This has intervention and policy implications, highlighting the need to address the social dimension of waterpipe smoking, in addition to targeted awareness with health warning labels. It is also worth noting that compared to both home and café smokers, smoking in 'other location' was associated with a higher motivation to quit in response to almost all the warning labels. Further exploratory research is needed to identify these locations (which could be any informal setting such as park, beach etc.) in order to develop suitable tobacco regulations.

Irrespective of the compliance of the waterpipe 
HWL with the FCTC recommendations on the tobacco pack, the lack of exposure to the tobacco pack in café settings means that a considerable proportion of the targeted population is not reached. In line with other studies ${ }^{9,20,21}$, we found that placing the HWL on the mouthpiece would make it most noticeable for both males and females. While a prior study suggested that this location would be the most effective for non-users ${ }^{16}$, our study suggests that placing a health warning on the mouthpiece is also effective for current waterpipe smokers. These variations emphasize the importance of targeted interventions and policies in café settings and those targeting café-only smokers. Our study also confirms previous policy recommendations related to placing the targeted HWL on the waterpipe device, especially the mouthpiece ${ }^{14,20,21}$.

\section{Strengths and limitations}

To our knowledge, this study is the first to evaluate motivation to quit waterpipe smoking in response to HWLs by gender and smoking location, thus, setting the stage for future studies among WTS in other regions. The sample size was sufficiently large giving the study sufficient power to detect significant differences between the groups being studied. Limitations include the possibility of response bias due to self-reporting as well as generalizability constraints due to the use of convenience sampling and the fact that the sample included only university students who may not be representative of the entire young adult population. Another limitation is that the survey did not include questions on nicotine addiction, frequency of smoking, years of smoking, which are variables that may have also impacted the motivation to quit in response to the exposure to the HWLs.

\section{CONCLUSIONS}

Our findings have implications on waterpipe smoking research, practice and policy. Health warning themes related to pregnancy and children's health were the most effective at motivating young adults to quit waterpipe smoking in all three countries with females being significantly more motivated than males in Palestine. This suggests the need for gender-specific and gender-targeted messaging and interventions when addressing intention to quit waterpipe smoking, as well as more investment in gender and feminist research to understand gender-specific variations in waterpipe smoking behaviors. Also, more theorydriven research would help elucidate the underlying factors associated with increased motivation to quit in response to HWLs. Variations in responses to HWLs by usual or preferred smoking location brings implications in the design and delivery of targeted interventions as well as regulatory policy recommendations, which need to address café and athome smoking setting patterns, as well as placement of HWLs on the waterpipe device.

\section{REFERENCES}

1. Maziak W, Taleb ZB, Bahelah R, et al. The global epidemiology of waterpipe smoking. Tob Control. 2015;24(Suppl 1):i3i12. doi:10.1136/tobaccocontrol-2014-051903

2. Jawad M, Charide R, Waziry R, Darzi A, Ballout RA, Akl EA. The prevalence and trends of waterpipe tobacco smoking: A systematic review. PLoS One. 2018;13(2):e0192191. doi:10.1371/journal.pone.0192191

3. Jawad M, Lee JT, Millett C. Waterpipe Tobacco Smoking Prevalence and Correlates in 25 Eastern Mediterranean and Eastern European Countries: Cross-Sectional Analysis of the Global Youth Tobacco Survey. Nicotine Tob Res. 2016;18(4):395-402. doi:10.1093/ntr/ntv101

4. Khabour OF, Alzoubi KH, Eissenberg T, et al. Waterpipe tobacco and cigarette smoking among university students in Jordan. Int J Tuberc Lung Dis. 2012;16(7):986-992. doi:10.5588/ijtld.11.0764

5. Kabbash IA, Saied SM. Perception and Practices of Shisha Smoking among Kafr El-Sheikh University Students, Egypt. Egyptian Journal of Community Medicine. 2020;38(2):58-69. doi:10.21608/EJCM.2020.89890

6. Nasser AMA, Geng Y, Al-Wesabi SA. The Prevalence of Smoking (Cigarette and Waterpipe) among University Students in Some Arab Countries: A Systematic Review. Asian Pac J Cancer Prev. 2020;21(3):583-591. doi:10.31557/APJCP.2020.21.3.583

7. Abu-Rmeileh NME, Alkhuffash O, Kheirallah K, et al. Harm perceptions of waterpipe tobacco smoking among university students in five Eastern Mediterranean Region countries: A cross-sectional study. Tob Induc Dis. 2018;16(May):1-11. doi:10.18332/tid/89966

8. Hamadeh RR, Lee J, Abu-Rmeileh NME, et al. Gender differences in waterpipe tobacco smoking among university students in four Eastern Mediterranean countries. Tob Induc Dis. 2020;18(December):1-12. doi:10.18332/tid/129266

9. Salloum RG, Abu-Rmeileh N, Hamadeh R, et al. PolicyRelevant Context of Waterpipe Tobacco Smoking among University Students in Six Countries Across the Eastern Mediterranean Region: A Qualitative Study. 
Asian Pac J Cancer Prev. 2017;18(9):2533-2540. doi:10.22034/APJCP.2017.18.9.2533

10. Kheirallah KA, Veeranki SP, Alzyoud S, et al. Collision of waterpipe and cigarette smoking epidemics among youth in Arab countries. J Subst Use. 2016;21(5):530-536. doi:10.3109/14659891.2015.1082159

11. Institute for Global Tobacco Control. State of Evidence Review: Health Warning Labels on Tobacco Products. Johns Hopkins Bloomberg School of Public Health; 2013. Accessed March 1, 2021. https:// www.globaltobaccocontrol.org/sites/default/files/ HealthWarnings_state_of_evidence_final_11_18_2013_ web_0.pdf

12. WHO Study Group on Tobacco Product Regulation (TobReg). Advisory note: Waterpipe tobacco smoking: health effects, research needs and recommended actions for regulators. 2nd ed. World Health Organization; 2015. Accessed March 1, 2021. https://apps.who.int/iris/ bitstream/handle/10665/161991/9789241508469_eng. pdf

13. Maziak W, Ben Taleb Z, Ebrahimi Kalan M, et al. Pictorial health warning labels on the waterpipe device are effective in reducing smoking satisfaction, puffing behaviour and exposure to $\mathrm{CO}$ : first evidence from a crossover clinical laboratory study. Tob Control. 2019;28(e1):e37-e42. doi:10.1136/tobaccocontrol-2018-054682

14. Islam F, Salloum RG, Nakkash R, Maziak W, Thrasher JF. Effectiveness of health warnings for waterpipe tobacco smoking among college students. Int J Public Health. 2016;61(6):709-715. doi:10.1007/s00038-016-0805-0

15. Kumar J. Exposure to Health Warning Labels on Waterpipe Tobacco Packages: An Application of the Modified Extended Parallel Process Model on Quitting Behavior from Three Waves of the PATH Study. Dissertation. The University of Memphis; 2019. Accessed March 1, 2021. https://search.proquest.com/ openview/92679362ccfca16ab2b32ab4f664cee3/

16. Darawad MW, Salloum R, Alhussami M, Maharmeh M. Evaluating health warning messages specific to waterpipe smoking among university students in Jordan. J Am Assoc Nurse Pract. 2019;31(2):133-138. doi:10.1097/JXX.0000000000000107

17. Hallit S, Layoun N, Malaeb D, et al. The impact of textual and pictorial warnings on tumbac (waterpipe tobacco) boxes on the motivation and intention to quit waterpipe smoking in Lebanon: a cross-sectional study. Environ Sci Pollut Res Int. 2019;26(36):36647-36657. doi:10.1007/s11356-019-06801-8

18. Nakkash R, Khalil J. Health warning labelling practices on narghile (shisha, hookah) waterpipe tobacco products and related accessories. Tob Control. 2010;19(3):235-239. doi:10.1136/tc.2009.031773

19. Jawad M, Bakir A, Ali M, Grant A. Impact of Waterpipe Tobacco Pack Health Warnings on Waterpipe Smoking Attitudes: A Qualitative Analysis among Regular
Users in London. Biomed Res Int. 2015;2015:1-6. doi:10.1155/2015/745865

20. Mostafa A, Mohammed HT. Graphic health warnings and their best position on waterpipes: A cross-sectional survey of expert and public opinion. Tob Prev Cessat. 2017;3(June):1-11. doi:10.18332/tpc/70873

21. Mostafa A, Mohammed HT, Hussein WM, et al. Would placing pictorial health warnings on waterpipe devices reduce waterpipe tobacco smoking? A qualitative exploration of Egyptian waterpipe smokers' and nonsmokers' responses. Tob Control. 2019;28(4):475-478. doi:10.1136/tobaccocontrol-2018-054494

22. Salloum RG, Lee J, Mostafa A, et al. Waterpipe Tobacco Smoking among University Students in Three Eastern Mediterranean Countries: Patterns, Place, and Price. Subst Use Misuse. 2019;54(14):2275-2283. doi:10.1080/10826084.2019.1645177

23. Afifi R, Khalil J, Fouad F, et al. Social norms and attitudes linked to waterpipe use in the Eastern Mediterranean Region. Soc Sci Med. 2013;98:125-34. doi:10.1016/j.socscimed.2013.09.007

24. Nakkash RT, Khalil J, Afifi RA. The rise in narghile (shisha, hookah) waterpipe tobacco smoking: a qualitative study of perceptions of smokers and non smokers. BMC Public Health. 2011;11:315. doi:10.1186/1471-2458-11-315

25. Ward KD, Eissenberg T, Gray JN, Srinivas V, Wilson N, Maziak W. Characteristics of U.S. waterpipe users: a preliminary report. Nicotine Tob Res. 2007;9(12):13391346. doi:10.1080/14622200701705019

26. Mostafa A, Mohammed HT, Hussein WM, et al. Plain packaging of waterpipe tobacco? A qualitative analysis exploring waterpipe smokers' and non-smokers' responses to enhanced versus existing pictorial health warnings in Egypt. BMJ Open. 2018;8(10):e023496. doi:10.1136/bmjopen-2018-023496

27. Nakkash R, Abu-Rmeileh N, Al-Farsi Y, et al. Evaluation of health warnings for waterpipe tobacco smoking among university students in the Eastern Mediterranean region. Tob Induc Dis. 2018;16(Suppl 1):295. doi:10.18332/ $\mathrm{tid} / 84636$

28. Mead EL, Cohen JE, Kennedy CE, Gallo J, Latkin CA. The role of theory-driven graphic warning labels in motivation to quit: a qualitative study on perceptions from low-income, urban smokers. BMC Public Health. 2015;15:92. doi:10.1186/s12889-015-1438-6

29. Kollath-Cattano C, Osman A, Thrasher JF. Evaluating the perceived effectiveness of pregnancy-related cigarette package health warning labels among different gender/age groups. Addict Behav. 2017;66:33-40. doi:10.1016/j.addbeh.2016.11.007

30. Asfar T, Schmidt M, Ebrahimi Kalan M, et al. Delphi study among international expert panel to develop waterpipespecific health warning labels. Tob Control. 2020;29(2):159167. doi:10.1136/tobaccocontrol-2018-054718

31. Jaber R, Madhivanan P, Khader Y, Mzayek F, Ward KD, 
Maziak W. Predictors of waterpipe smoking progression among youth in Irbid, Jordan: A longitudinal study (2008-2011). Drug Alcohol Depend. 2015;153:265-270. doi:10.1016/j.drugalcdep.2015.05.008

32. Koval JJ, Aubut JA, Pederson LL, O'Hegarty M, Chan SS. The potential effectiveness of warning labels on cigarette packages: the perceptions of young adult Canadians. Can J Public Health. 2005;96(5):353-356. doi:10.1007/BF03404031

33. Alanazi NH, Lee JW, Dos Santos H, Job JS, Bahjri K. The use of planned behavior theory in predicting cigarette smoking among Waterpipe smokers. Tob Induc Dis. 2017;15(July):1-8. doi:10.1186/s12971-017-0133-z

34. Asfar T, Ward KD, Eissenberg T, Maziak W. Comparison of patterns of use, beliefs, and attitudes related to waterpipe between beginning and established smokers. BMC Public Health. 2005;5(1):19. doi:10.1186/1471-2458-5-19

\section{ACKNOWLEDGEMENTS}

The authors acknowledge the following individuals and research teams for their contributions to the data collection phase of this study: Mostafa Elshahed and Marwa Nofal on behalf of the Medical Students Awareness Group 'Arabicrosheta' (Ain Shams University, Egypt); Rula Ghandour and Marina Touktouk (Birzeit University, Palestine); and the International Federation of Medical Students Association-Jordan/Jordan University of Science and Technology Local community (IFMSA-JO/JUST-Lc).

\section{CONFLICTS OF INTEREST}

The authors have each completed and submitted an ICMJE form for disclosure of potential conflicts of interest. The authors declare that they have no competing interests, financial or otherwise, related to the current work. R. Salloum reports grants from IDCR during the conduct of the study. G. Khawam reports fees from American University of Beirut during the conduct of the study, and other from Saint Joseph University (USJ), outside the submitted work. G. Khawam also serves as a board member at Lebanese Down Syndrome Association (LDSA), and as a committee member at Lebanon Disability Hub.

\section{FUNDING}

This work was supported by the International Development Research Center (Canada) under Grant no. 106981-001. The funding source had no involvement in study design, collection, analysis, and interpretation of the data, in writing the manuscript, and decision to submit for publication.

\section{ETHICAL APPROVAL AND INFORMED CONSENT}

The study protocol was approved by the institutional review boards of all participating universities. All participants provided informed consent before acquiring access to the online survey.

\section{AUTHORS' CONTRIBUTIONS}

Design and conception of the study: RGS, RN, JFT, RRH. Acquisition of data: NA-R, MWD, AM, KAK, MS. Data analysis: JL, DF, RGS, GK. Manuscript drafting and revision: all authors. Final approval of manuscript: all authors.

PROVENANCE AND PEER REVIEW

Not commissioned; externally peer reviewed. 